\title{
TESTING THE EFFICIENCY OF FENTON'S REAGENT IN TREATMENT OF PETROLEUM-CONTAMINATED SAND
}

\author{
ValériaS. Millioli, Denize D. C. Freire \\ Magali C. Cammarota \\ Escola de Química, \\ Universidade Federal do Rio de Janeiro \\ Cidade Universitária - CT - Bl. E - Lab.115- Ilha \\ do Fundão, Rio de Janeiro, R.J. (Brazil). \\ ZIP: 21949-900, Phone.: (5521) 25627568 - \\ Fax: (5521) 25627567 \\ christe@eq.ufrj.br
}

\begin{abstract}
The removal of petroleum of beach sand after an oil spill in Guanabara Bay, Rio de Janeiro (Brazil) was studied using Fenton's reagent $\left(\mathrm{Fe}^{2+}+\mathrm{H}_{2} \mathrm{O}_{2}\right)$ with $\mathrm{H}_{2} \mathrm{O}_{2}$ concentrations of $0.4 \mathrm{M}$ and $4.0 \mathrm{M}$ and $\mathrm{Fe}^{2+}$ concentrations of $2.7 \mathrm{~g} / \mathrm{L}$ and $27.2 \mathrm{~g} /$ L. The initial Oil \& Grease (O\&G) content in the contaminated sand was $32 \mathrm{~g} / \mathrm{kg}$ sand. The maximum O\&G removal obtained was $97 \%$ after Fenton's reaction. An analysis of the supernatant after the reaction showed that it was biodegradable. Chromatographic analysis indicated that Fenton's reaction favored the modification and reduction of the fractions of saturated and aromatic hydrocarbons in the oil.

Key words: Fenton's reagent, petroleum, beach sand
\end{abstract}

\section{INTRODUCTION}

In January 2000, there was a large-scale oil spill in Guanabara Bay, when around 1.3 million barrels of crude oil leaked out of a pipeline, affecting beaches and mangroves. After it reached the beaches, the oil was removed together with the sand with spades, constituting a hazardous waste. This waste is being stored until a treatment method or means of recuperating the oil is found at a reasonable cost. One of the treatment processes that seems promising for the precipitation and/or mineralization of various organic contaminants is chemical oxidation using Fenton's reagent 1,2,3,4.

The decontamination of soils with Fenton's reagent has been investigated as an alternative process in the remediation of sites contaminated with organic compounds. The obtainment of a strong oxidant (radical $\mathrm{OH} \bullet$ ) capable of destroying or hydrolyzing many of these compounds in contaminated soils by decomposing $\mathrm{H}_{2} \mathrm{O}_{2}$ is shown as follows:

$$
\mathrm{Fe}^{2+}+\mathrm{H}_{2} \mathrm{O}_{2} \rightarrow \mathrm{Fe}^{3+}+\mathrm{OH} \bullet+\mathrm{OH}^{-}
$$

Initially, Fenton's reaction was employed in the oxidation of compounds soluble in water, like alcohols and phenol. The greatest difference when it comes to contaminated soils is the physical state of the contaminant. While in aqueous systems the contaminant is soluble in water, in soil it is adsorbed or present as particles into soil matrix ${ }^{5}$. The physical state of these contaminants hampers treatment conditions, requiring a more rigorous process than that applied in the classic Fenton's reaction, which involves the addition of diluted hydrogen peroxide ${ }^{6}$.

\section{MATERIALS AND METHODS}

Contaminated beach sand: The beach sand contaminated with petroleum collected after the spill was granted by CENPES (Centro de Pesquisas Leopoldo Miguez Petrobrás). The sand's initial O\&G content was $32 \mathrm{~g} / \mathrm{kg}$ sand. Before being analyzed, the sand was quartered to obtain a representative sample ${ }^{7}$. According to the PETROBRÁS ${ }^{8}$ data, the oil contained $44 \%$ aromatic compounds, $31 \%$ resins, $14 \%$ asphaltenes and $11 \%$ saturated hydrocarbons.

Analytical methodology: The $\mathrm{H}_{2} \mathrm{O}_{2}$ was quantified by titrimetric analysis with permanganate ${ }^{9}$. To analyze the O\&G levels, a Soxhlet extraction method was used, adapted for the soil sample ${ }^{10}$. To analyze the COD, the closed reflux method was used ${ }^{10}$. The interference of $\mathrm{H}_{2} \mathrm{O}_{2}$ in determining the COD was corrected using the equation by Talini \& Anderson ${ }^{11}$. The chromatographic analyses were conducted in an HP 5890 A chromatograph, using an SE-54 column (methyl 5\% phenyl silicone). After Fenton's reaction, the oil was extracted from the sand and the fractions of saturated and aromatic hydrocarbons were separated according to the methodology employed by Olson et al. ${ }^{12}$. After the solvent was evaporated, the oil was diluted in dichloromethane $(1 \mathrm{mg} / 10 \mathrm{~mL})$ and injected into the chromatograph.

Analysis of biodegradability of the aqueous phase: Biodegradability tests on the aqueous phase separated after 
chemical oxidation were carried out using a bioreactor with a working volume of $500 \mathrm{~mL}$, using activated sludge from a sewage treatment plant $(\mathrm{VSS}=2210 \mathrm{mg} / \mathrm{L})$ that had been adapted previously. After nutrients $\mathrm{KH}_{2} \mathrm{PO}_{4}$ and urea were added (COD:N:P =100:5:1) and the $\mathrm{pH}$ adjusted to 7.0, the aqueous phase was mixed with the sludge and aerated. Samples of the aqueous phase were taken every $2 \mathrm{~h}$ to measure the soluble COD.

Tests with Fenton's reagent: The experiments carried out with Fenton's reagent were conducted at ambient temperature $\left(25 \pm 2{ }^{\circ} \mathrm{C}\right)$, with constant shaking $(70 \mathrm{rpm})$ in a jar test. They were done in $1000 \mathrm{~mL}$ glass beakers with a $12 \mathrm{~cm}$ diameter. To these beakers were added $5 \mathrm{~g}$ or $20 \mathrm{~g}$ sand in $200 \mathrm{~mL}$ of a solution containing iron (II) sulfate heptahydrate $1 \mathrm{~N}$ and hydrogen peroxide $(30 \%, \mathrm{v} / \mathrm{v})$ in different proportions. The concentrations of $\mathrm{H}_{2} \mathrm{O}_{2}$ used were $0.4 \mathrm{M}$ or $4.0 \mathrm{M}$ and of $\mathrm{Fe}^{2+}$ were $2.7 \mathrm{~g} / \mathrm{L}$ or $27.2 \mathrm{~g} / \mathrm{L}$. The reaction times investigated for the removal of oil from the sand were $3 \mathrm{~h}$ and $6 \mathrm{~h}$. The $\mathrm{pH}$, was initially adjusted to 3.0, and was thereafter adjusted each hour. The $\mathrm{H}_{2} \mathrm{O}_{2}$ was added to the medium slowly for $3 \mathrm{~h}$.

Experimental design: The effect of the different factors on the removal of oil from the sand was evaluated through a fractionary experimental design $2^{(4-1)}$ with three central points, developed in accordance with the methodology proposed by Montgomery ${ }^{13}$. The factors selected were: $\mathrm{H}_{2} \mathrm{O}_{2}$ concentration, $\mathrm{Fe}^{2+}$ concentration, mass of contaminated sand and reaction time. The O\&G removal results were analyzed using Statistica 5.5 software to determine the most significant factors and/or interactions involved in the removal of oil from the sand.

\begin{tabular}{c|c|c|c|c|c}
\hline $\mathrm{RUN}$ & $\mathrm{H}_{2} \mathrm{O}_{2}(\mathrm{M})$ & $\mathrm{Fe}^{2+}(\mathrm{g} / \mathrm{L})$ & SAND (g/L) & TIME (h) & $\begin{array}{c}\text { REM. } \\
\text { EFF. } \%)\end{array}$ \\
\hline 1 & 4 & 27.2 & 100 & 6 & 95 \\
\hline 2 & 4 & 2.7 & 25 & 6 & 97 \\
\hline 3 & 0.4 & 27.2 & 25 & 6 & 62 \\
\hline 4 & 0.4 & 2.7 & 100 & 6 & 78 \\
\hline 5 & 4 & 27.2 & 25 & 3 & 79 \\
\hline 6 & 4 & 2.7 & 100 & 3 & 91 \\
\hline 7 & 0.4 & 27.2 & 25 & 3 & 60 \\
\hline 8 & 0.4 & 2.7 & 25 & 3 & 54 \\
\hline 9 & 2.2 & 14.5 & 62.5 & 4.5 & 65 \\
\hline 10 & 2.2 & 14.5 & 62.5 & 4.5 & 68 \\
\hline 11 & 2.2 & 14.5 & 62.5 & 4.5 & 68 \\
\hline
\end{tabular}

Table 1 - Results referring to the O\&G removal efficiency from sand in the fractionary experimental design $2^{(4-1)}$

\section{RESULTS AND DISCUSSION}

Analysis of the Experimental Design: A statistical analysis of the results generated linear regression with a correlation coefficient of 0.99 for a confidence level of $95 \%$. The 11 experiments with their respective results are presented in Table 1. It can be seen that the O\&G removal efficiency varied between $54 \%$ and $97 \%$. These results show that the oil came away well from the sand, moving to the aqueous phase, which reduced the toxicity of this residue and made its final disposal easier.

The Student t-test was used to verify which effects were significant in the oil removal efficiency, the results of which are presented as a Pareto graph in Figure 1. An analysis of the Pareto graph indicated that to obtain greater oil removal, the reaction must be conducted with higher $\mathrm{H}_{2} \mathrm{O}_{2}$ concentrations, a longer reaction time and lower $\mathrm{Fe}^{2+}$ concentration. Watts \& Stanton ${ }^{14}$ observed that high $\mathrm{H}_{2} \mathrm{O}_{2}$ concentrations, of around $10 \mathrm{M}$, brought about a greater desorption and oxidation of hexadecane in sand (silica). The mass of sand analyzed in these experiments was not significant, yet it had a negative effect, indicating that it could be advantageous to work with smaller masses to achieve better oil removal from the sand.

In other tests, the fractions of oil were analyzed (oil adhered on the sand + dissolved oil + emulsified and free oil), after the treatment with Fenton, as shown in Table 2.

It can be seen that little oil remained in the soil after the chemical oxidation (only $19 \%$ of the total O\&G content), i.e. $81 \%$ of the oil was removed from the sand. Most of the oil

\begin{tabular}{|c|c|c|c|c|c|}
\hline Tests ${ }^{(1)}$ & $\begin{array}{l}\% \text { oil in the } \\
\text { sandy soil } \\
\text { (A) }\end{array}$ & $\begin{array}{l}\text { \% soluble oil in } \\
\text { aqueous phase } \\
\text { (B) }\end{array}$ & $\begin{array}{l}\% \text { free and } \\
\text { emulsified oil in } \\
\text { aqueous phase } \\
\text { (C) }\end{array}$ & $\begin{array}{l}\begin{array}{c}\% \text { oil after Fenton } \\
\text { treatment }\end{array} \\
D=(\quad A+B+C)\end{array}$ & $\begin{array}{c}\begin{array}{c}\text { Overall O\&G } \\
\text { oxidation eff. } \\
(\%)^{(2)} \\
(100-D)\end{array}\end{array}$ \\
\hline 1 & 18.0 & 1.5 & 48.0 & 67.5 & 32.5 \\
\hline 2 & 22.0 & 1.0 & 41.0 & 64.0 & 36.0 \\
\hline 3 & 17.0 & 2.5 & 44.0 & 63.5 & 36.5 \\
\hline Average & 19.0 & 1.2 & 44.3 & 64.7 & 35.3 \\
\hline
\end{tabular}

Table 2 - Results showing fractions of oil in the different phases, soon after the Fenton reaction, in a sample with an initial O\&G level of $32 \mathrm{~g} / \mathrm{kg}$ sand.

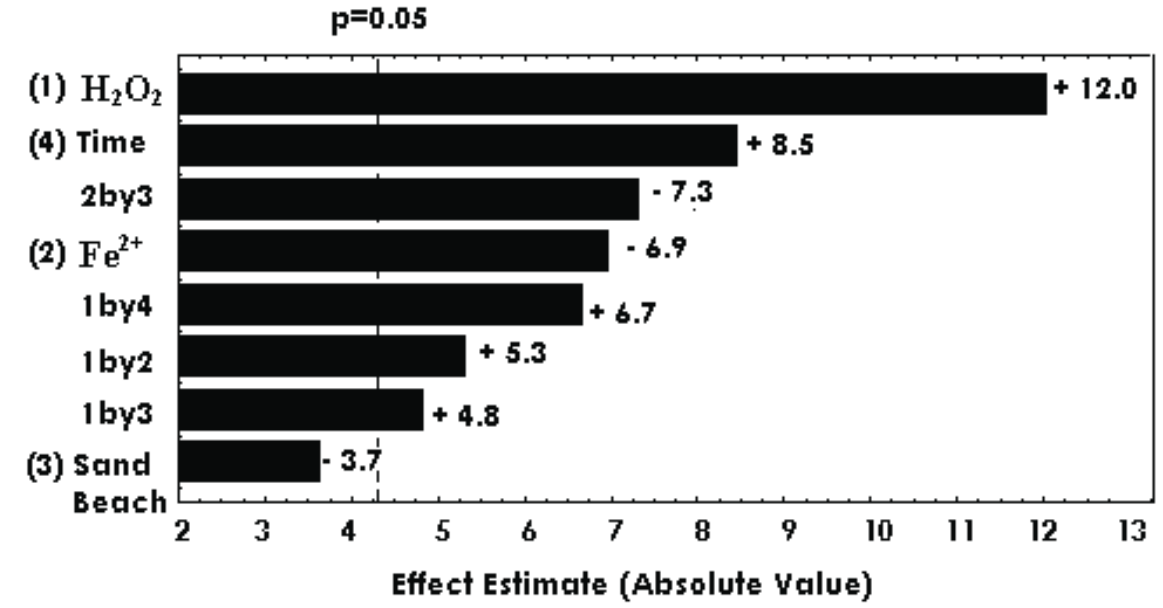

Fig. 1 - Pareto graph for the O\&G removal efficiency from sand using Fenton"s reagente $\left(1=\mathrm{H}_{2} \mathrm{O}_{2} ; 2=\right.$ iron; $3=$ sand; $4=$ time $)$. 
remained emulsified (44.3\%), which made its removal from the medium easier. The total oil oxidation efficiency was obtained for the total oil content $(100 \%-a ̊ A+B+C)$ that remained in the solution after treatment with Fenton's reagent. In this way, it was verified that on average only $35.3 \%$ of the O\&G present in the sand was mineralized by Fenton's reaction under the conditions analyzed.

Analysis of biodegradability in the aqueous phase: New experiments were held under the best conditions supplied by the Pareto graph (Run 2 - Table 1). The resulting aqueous phase was analyzed as to its biodegradability. The aqueous phase, which contained only dissolved and emulsified oil, presented a residual $\mathrm{H}_{2} \mathrm{O}_{2}$ concentration of $500 \mathrm{mg} / \mathrm{L}$ and COD of $542 \mathrm{mg} / \mathrm{L}$ (corrected value). Figure 2 shows the decay of soluble COD from the aqueous phase with time.

It can be seen in Figure 2 that the aqueous solution that resulted from Fenton's reaction was biodegradable, since by around $7.5 \mathrm{~h}$, the COD level had already been reduced by $60 \%$. Chamarro et al. ${ }^{15}$ also observed reductions in COD after Fenton's reaction with different organic compounds (formic acid, phenol, 4-chlorophenol, 2.4-dichlorophenol and nitrobenzene).

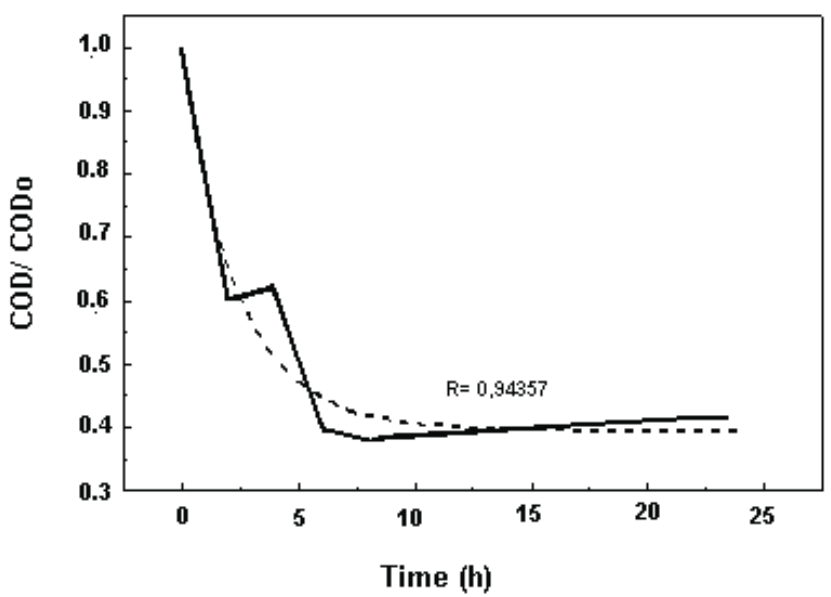

Fig. 2 - Biodegradability curve of the aqueous phase after Fento"s reation. Inoculum $=$ activated sludge $(\mathrm{VSS}=2210 \mathrm{mg} / \mathrm{L})$; aqueous phase supplemented with nutrientes (COD: $\mathrm{N}: \mathrm{P}=100: 5: 1)$, with $\mathrm{pH}$ adjusted to 7.0.

Analysis of the oxidation by gas chromatography: The oxidation of the oil was investigated using gas chromatography of the extracts obtained after Fenton's reaction, conducted under the best (Run 2) and worst (Run 8) oil removal conditions (Table 1). The purpose of these analyses was to verify whether the oxidation of the oil by Fenton's reaction was closely related to the oil removal from the sand.

Figure 3 shows the fractions of saturated and aromatic hydrocarbons before and after Fenton's reaction for the best and worst experimental conditions. The chromatograms of the oil treated under the best removal conditions (chromatograms $\mathrm{S}_{1}$ and $\mathrm{A}_{1}$ ) show that there was a greater modification in the composition of the oil and a greater reduction in the fractions of saturated and aromatic hydrocarbons than was observed under the worst removal conditions (chromatograms $\mathrm{S}_{2}$ and $\mathrm{A}_{2}$ ), when both are compared with the chromatograms obtained for the untreated oil $\left(S_{0}\right.$ and $\left.A_{0}\right)$. These modifications could be

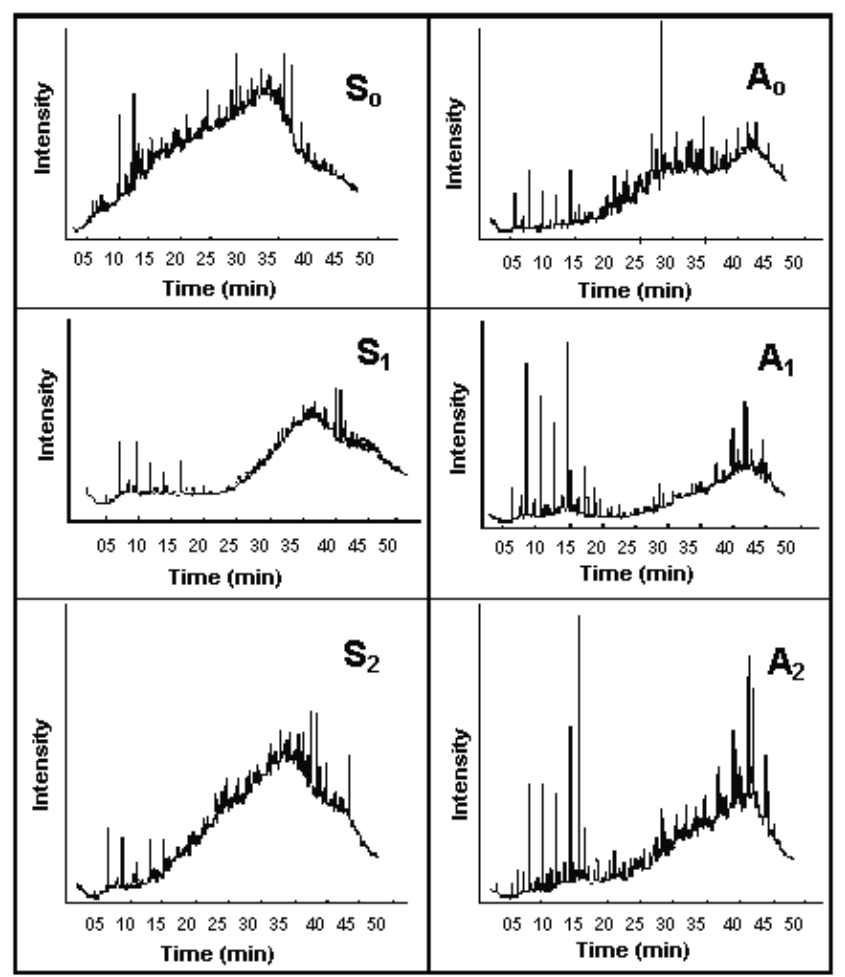

Figure 3: Chromatographic analysis of the oil before and after Fenton's reaction under the best and worst oil removal conditions. Indices: A - saturated hydrocarbons, B - aromatic hydrocarbons, 0 - before the reaction, 1 - after the reaction under the best removal condition, 3 - after the reaction under the worst removal condition.

closely related to the removal of oil from the sand. In other words, for there to be a greater oxidation of the hydrophobic contaminants present in the soil, it is necessary for the oil to be removed from the sand so it can be in contact with the reactive species in the solution and the oxidation process can begin. The need for there to be oil removal for there to later be oxidation was reported by other authors ${ }^{1,14}$.

\section{CONCLUSIONS}

In the analysis of the removal efficiency of oil from the sand, efficiency levels of between $54 \%$ and $97 \%$ were achieved, indicating that Fenton's reaction was effective in cleaning the beach sand. Analyses made on the supernatant after Fenton's reaction indicated a $60 \%$ COD reduction after around $7.5 \mathrm{~h}$, which implies that the effluent generated was biodegradable. The chromatographic analysis indicated that Fenton's reaction made it possible to modify the fractions of saturated and aromatic hydrocarbons when there was a higher proportion of oil removed from the sand.

\section{ACKNOWLEDGEMENTS}

The authors wish to thank CENPES (PETROBRAS) for the sand samples and for supplying the data necessary for the experiments, Alberto dos Santos (LADETEC/IQ/UFRJ) for the gas chromatography analyses and CAPES for the financial support. 


\section{REFERENCES}

1 - Watts, R.J. ; Kong, S. Dippre, M.; Barnes, W.T. J. Hazard. Mater. 1994. 41, 105.

2 - Watts, R.J.; Foget, M.K.; Kong, G, S-H.; Teel, A.L J. Hazard. Mater. 1999. B69, 229.

3 - Watts, R.J.; Haller, D.R.; Jones, A.P.; Teel, A.L. J. harzard. Mater. 2000. B76, 73.

4 - Kong, S.; Watts, R.J.; Choi, J. Chemosphere. 1998. 37(8), 1473.

5 - Watts, R.J.; Udell, M.D.; Monsen, R.M. Water Environ. Res. 1993. 65 (7), 839

6 - Walling, C. Acc. Chem. Res.. 1975. 8, 125.

7 - ABNT(Associação Brasileira de Normas Técnicas). 1987. NBR 10007.

8 - PETROBRÁS. Caracterização preliminar do impacto da vazamento acidental de óleo ocorrido em 18/01/2000 na Baía de Guanabara. Fev. 2000.
9 - Morita, T.; \& Assumpção, R.M.V. Manual de soluções, reagentes \& solventes. $2^{\mathrm{a}}$ ed. Ed. Edgard Blucher LTDA. 1981.

10 - APHA, AWWA, WPCF. Standard Methods for the examination of water and wastewater. $18^{\text {th }}$ edition, New York. 1992.

11 - Talini, I. \& Anderson, G.K. Water Res. 1992. 26(1), 107

12 - Olson, J.J.; Mills, G. L.; Herbert, B.E.; Morris, P.J. Environ. Toxicol. Chem.. 1999. 18(11), 2448.

13- Montgomery, D.C. Design and analysis of experiments. Third edition, John Wiley \& Sons. New York. 1991.

14 - Watts, R.J.; Stanton, P.C. Water Res. 1999.33 (6), 1405.

15 - Chamarro, E.; Marco A.; Espugas, S Water Res. 2001. 35 (4), 1047. 